Review of Quantitative Finance and Accounting, 17: 397-420, 2001

(C) 2001 Kluwer Academic Publishers. Manufactured in The Netherlands.

\title{
Cost Inefficiency, Size of Firms and Takeovers
}

\author{
SUSANNE TRIMBATH \\ Research Economist, Milken Institute, 1250 4th Street, Santa Monica, \\ CA 90401. 310-998-8449
}

HALINA FRYDMAN

Associate Professor, Stern School of Business, New York University, New York, NY 10003. 212-998-0453

ROMAN FRYDMAN

Professor, Department of Economics, New York University, New York, NY 10003. 212-998-8967

\begin{abstract}
This study, using the Cox proportional hazards model, finds that the risk of takeover rises with cost inefficiency. It also finds that a firm faces a significantly higher risk of takeover if its cost performance lags behind its industry benchmark. Moreover, these findings appear to be remarkably stable over the nearly two decades spanned by the sample. The effect of the variables used to measure the risk-size relationship, however, indicates temporal changes. Lastly, the study presents evidence from fixed-effects models of ex post cost efficiency improvements that support the hypothesis that takeover targets are selected based on the potential for improvement.
\end{abstract}

Key words: corporate finance and governance, mergers, acquisitions, econometric methods, models with panel data, truncated and censored models.

JEL Classification: G3, G34, C2, C23, C24

Corporate takeovers have been a permanent feature of the American business landscape since the mid-1800s (Pound, 1992). Mergers and acquisitions continue to play an important role in allocating resources in the U.S. economy. The same number of mergers and acquisitions were completed in the first five years of the 1990s - about 23,000 - as in the entire previous decade (Mergers and Acquisitions, September-October, 1995). Furthermore, in the peak years of each decade, the value of takeovers equaled about one-fourth of GNP (Fortune, March 2, 1998.)

The prominent role of takeovers in reallocating control over capital in the U.S. economy has generated vigorous debate over whether takeovers actually improve efficiency. Two issues dominate the debate: the pre-takeover performance of targets and the post-takeover changes in performance. As discussed in more detail in the next section, earlier studies of the ex ante performance of target firms did not reach a definitive conclusion about the effect of efficiency on the risk of takeover. Moreover, there is no consensus on the ex post effect of takeovers on firm performance. 
A variety of variables were used to measure performance across the different sample periods in takeover studies. The examination of measures of profit and market value as performance measures in this study did not yield consistent results (Trimbath, Frydman and Frydman, 2000), however, one measure of performance that did provide consistent, stable results over time was cost inefficiency. ${ }^{1}$ We present those results here.

This study demonstrates that a temporally consistent contributing factor to a firm's risk of takeover is the relatively inefficient use of resources, and that the combination of firms in a takeover results in the ex post improvement in cost efficiency as measured by the cost per unit of revenue. The bearing of cost inefficiency on the risk of takeover and the resulting improvements in cost efficiency appear to be remarkably stable over the nearly two decades examined.

The paper also investigates the effect of firm size on the risk of takeover. Prior analyses of takeovers suggest and often find that size has a negative effect on the risk of takeover. (See, for example, Singh, 1975; Hasbrouck, 1985). This negative effect of size on risk has been attributed to the difficulties in financing large takeover transactions. However, size may also have a positive effect on risk. The specification of our model, therefore, has been designed to test for such a possibility. Since the cost variable includes overhead costs, and post-takeover cost restructuring is likely to entail economies of scale, the marginal increase in size tends to enhance the potential for post-takeover savings in cost per unit of revenue. Thus, the effect of size on the risk of takeover can be positive or negative. It is also expected to vary over time depending on the accessibility of financing for corporate control activity and the relative strength of the opposing effects. Evidence consistent with this interpretation is presented: while the effect of firm size on the risk of takeover is always significant, the magnitude and the sign of this effect are significantly different across the sample period. ${ }^{2}$

The literature on takeovers has predominately used logistic and probit regressions to analyze takeover data. ${ }^{3}$ These techniques estimate the probability of takeover over a fixed period as a function of a firm's characteristics at the beginning of the period. As such, these techniques are not suitable for an investigation of the temporal profile of risk. This paper employs the Cox regression model, which is particularly appropriate for the study of a time-varying risk profile. The Cox model is a dynamic technique that incorporates time-dependent covariates and estimates the hazard rate of takeover at any time during the study period as a function of these covariates. To study the ex post effect of takeovers, this study uses fixed-effects panel data models that control for how firms performed before the takeover occurred.

This paper is organized into six sections. The first section summarizes prior studies on takeovers. The second section describes the sample, defines the efficiency measure and looks briefly at descriptive statistics for our analysis of the ex ante determinants of takeover risk. The third section introduces the Cox regression model and discusses the results of estimations of alternative specifications of models for the risk of takeover. The fourth section describes the modifications made to the data set for our analysis of the ex post effect of takeovers on firm performance. The fifth section applies the fixed-effects panel data model and presents the results of regressions for models of the takeover effect on firm performance. The final section concludes. 


\section{Literature review}

The debate about the determinants and effects of takeovers in the United States is rekindled with the peak of each new wave of takeovers. And with each new wave of takeover studies come additional conflicting results. This section does not give an exhaustive review of the literature on takeovers. Rather, it provides a sampling of those that assumed to study the same phenomenon but arrived at different conclusions.

Ravenscraft and Scherer (1987) argue that prior to the 1980s, target firms were often more profitable than non-target firms. Billett (1996) suggests that from 1977-1986, they were equally profitable, and Cheh, Weinberg and Yook (1999) present evidence that in 1985-1993 targets were less profitable than non-target firms. Using various measures of market valuation as a proxy for performance (market-to-book, Tobin's Q, etc.), some studies report that prior to and during the 1980s, the performance of targets was not significantly different from non-target firms (Mueller, 1980; Palepu, 1986; Powell, 1997; Ambrose and Megginson, 1992; Cudd and Duggal, 2000). Still others report a relatively lower valuation for target firms in the 1980s (Hasbrouck, 1985; Mørck et al., 1989; Davis and Stout, 1992; Cheh, Weinberg and Yook, 1999).

In ex post examinations, Meeks (1977) finds no consistent change in performance resulting from takeovers, whereas Mueller (1980), and Ravenscraft and Sherer (1987), find a significant deterioration in performance. ${ }^{4}$ Three later studies-Healy et al. (1992), Lichtenberg (1992), and Switzer (1996) — find significant ex post performance improvements resulting from takeovers. ${ }^{5}$

Given the lack of consistent evidence in aggregate data sets, empirical researchers turned to sorting takeovers into different events. The suggestion was that the true determinants of the probability of takeover were masked within these sub-categories. Most notably, Mørck, Shleifer and Vishny (1988) separated targets by "mood," determined by the target's reaction to the first bid received before it was taken over. Rejection of a takeover offer was hypothesized to be the action of poor performing managers protecting their jobs. Categorical divisions of takeovers also did not produce consistent empirical results. The targets of hostile takeovers are reported to be poor performers (Mørck, Shleifer and Vishny, 1988; Martin and McConnell, 1991), better performers (Herman and Lowenstein, 1988; Powell, 1997) and not different from other firms (Davis and Stout, 1992; Kennedy and Limmack, 1996). Analyses separating ex post profitability by the "mood" of the takeover produce similar conflicts (Fowler and Schmidt, 1989; Healy et al., 1992; Powell, 1997). The theories and evidence of the implications for target management dismissals (another definition of "hostile") on ex post performance are also mixed. (Cannella and Hambrick, 1993) provide a summary of eight arguments, with predicted results of negative, positive and neutral, along with a bibliography of empirical findings.) Empirical studies using another popular categorization (relatedness of target and buyer industry) show variously that relatedness decreases ex post shareholder returns (Agrawal et al., 1992), improves ex post returns (Kusewitt, 1985) or has no significant effect (Fowler and Schmidt, 1989; Cannella and Hambrick, 1993).

Whether the debate will be resolved through the use of new or better performance measures, more advanced methodology or unidentified categorizations remains to be seen. The 
present research seeks to contribute both methodology and measurement to the debate on the determinants and effects of takeovers in the United States.

\section{Data for the ex ante analysis}

This study is based on a sample of U.S. corporations included in the Fortune 500 ranking at least one year between 1980 and 1997. Separate methodologies were applied to our analysis of the determinants and the effects of takeovers thus, certain modifications to the data set were necessary for the ex post analysis. These are discussed later. The following describes the overall sample and the construction of data observations applicable to both studies generally and the ex ante analysis specifically.

\section{Sample and data description}

The Compustat files contained 1,092 firms that ranked in the Fortune 500 at least one year between 1980 and 1997. After excluding non-publicly traded companies ${ }^{6}$ and financial firms from the study, 938 firms remained. Takeovers - defined as a transaction in which one firm is subsumed into another, i.e., where a complete change of ownership occurs-were tracked each year from 1981 through $1997 .{ }^{7} 318$ firms were identified as targets.

All performance data from 1980 through 1996 are taken from the Compustat files. For 57 targets, data for the year prior to takeover came from Moody's Industrial Manuals and SEC reports, when it was not available in Compustat. Industry adjustments are based on the median performance for each year of firms in the Compustat files with the same 2-digit SIC code. We required a minimum of 10 observations for each industry-year for the industry adjustments. Lack of industry medians reduced the sample to 896 firms and 276 takeovers. Our data set contains 10,784 observations.

Each firm was assigned to one of six sectors based on its industry: basic resources, cyclical consumer products, non-cyclical consumer products, energy, industrial, and technology. The sectors follow the definitions used in the Dow Jones Stoxx Index and are used to control for sector-specific effects on firm performance and the risk of takeover.

It is worth noting the difference between the 2-digit SIC code industries and the broader sectors. SIC industry codes, even at the 2-digit level, are specific enough that different codes are assigned, for example, to clothing wholesalers and clothing manufacturers. Sectors, on the other hand, gather all firms in the clothing industry together (cyclical consumer products). The industry adjustment is meant to make firm performance comparable across industries. Wholesalers and manufacturers face different cost structures, so that an adjustment based on the SIC code is appropriate for measures of performance. Descriptions of the sectors and the sectoral distribution of sample firms are summarized in Table 1 below and in Table A-1 in the Appendix.

The effects of cost efficiency on the risk of takeover are examined here. Cost per unit of revenue is measured as (cost of goods sold + selling, general and administrative expenses) divided by (net sales). To gauge the performance of a firm relative to similar firms, our 
Table 1. Sectors

The sectors are described in this table by the industries that are assigned to each. Every firm in the study is assigned to one of six sectors based on its industry. The sectors follow the definitions used in the Dow Jones Stoxx Index.

\begin{tabular}{|c|c|}
\hline & Description \\
\hline Sector 1: Basic Resources & $\begin{array}{l}\text { Forest products, Mining diversified, Non-ferrous metals, Paper products, } \\
\text { Precious metals, Steel, Chemicals }\end{array}$ \\
\hline $\begin{array}{l}\text { Sector 2: Cyclical Consumer } \\
\quad \text { Products }\end{array}$ & $\begin{array}{l}\text { Auto parts \& equipment, Auto manufacturers, Airlines, Entertainment \& leisure, } \\
\text { Home furnishings \& appliances, Home construction, Lodging, Textiles \& } \\
\text { apparel, Media, Broadline retailers, Specialty retailers }\end{array}$ \\
\hline $\begin{array}{l}\text { Sector 3: Non-cyclical } \\
\text { Consumer Products }\end{array}$ & $\begin{array}{l}\text { Cosmetics \& personal care, Food retailers \& wholesalers, Consumer \& } \\
\text { household products \& services, Medical supplies, Tobacco, Health care } \\
\text { providers, Beverages, Pharmaceuticals }\end{array}$ \\
\hline Sector 4: Energy & Coal, Oilfield equipment \& services, Oil companies, Pipelines \\
\hline Sector 5: Industrial & $\begin{array}{l}\text { Building materials, Heavy construction, Air freight \& couriers, Containers \& } \\
\text { packaging, Electric components \& equipment, Factory equipment, Diversified } \\
\text { industrials, Heavy machinery, Marine transportation, Industrial \& } \\
\text { commercial services, Trucking, Transportation equipment }\end{array}$ \\
\hline Sector 6: Technology & $\begin{array}{l}\text { Aerospace \& defense, Communication technology, Computers, Diversified } \\
\text { technology, Industrial technology, Medical \& biological technology, Office } \\
\text { equipment, Software }\end{array}$ \\
\hline
\end{tabular}

study used the industry-adjusted measure of performance: the industry median (computed as described above) subtracted from the observation of a firm's cost per unit of revenue. ${ }^{8}$

Previous corporate takeover studies interpreted cost per unit of revenue as proxies for cash flow or profitability. ${ }^{9}$ However, cost efficiency relative to the industry standard may provide a relatively reliable measure of the prospective gain from post-takeover cost restructuring of a target. Therefore, the industry-adjusted cost per unit of revenue may be an important determinant of the risk of takeover and it should not be necessarily considered as just a proxy for profitability. ${ }^{10}$

In addition to the performance measure, we used revenue (net sales) in constant 1980 dollars as a measure of the size of firms. ${ }^{11}$ Beyond controlling for firm size, the deflated revenue variable also provides information, complementary to the cost per unit of revenue, on the potential gains from a takeover of a relatively inefficient target. ${ }^{12}$ Earlier studies often interpreted the significance of the size variable in relation to capital market constraints. ${ }^{13}$ Both of these interpretations motivate our use of the unadjusted, rather than industryadjusted, size variable in our hazard models. ${ }^{14}$

\section{Descriptive statistics}

The simple annual hazard rate, defined as the number of targets as a percent of the number of firms under study each year, is displayed in Figure 1. A striking feature of Figure 1 is that the hazard rate falls precipitously after 1989, after increasing, albeit at a decreasing rate, in the earlier part of the 1980s. Indeed the average hazard rate of 3.4 percent per 


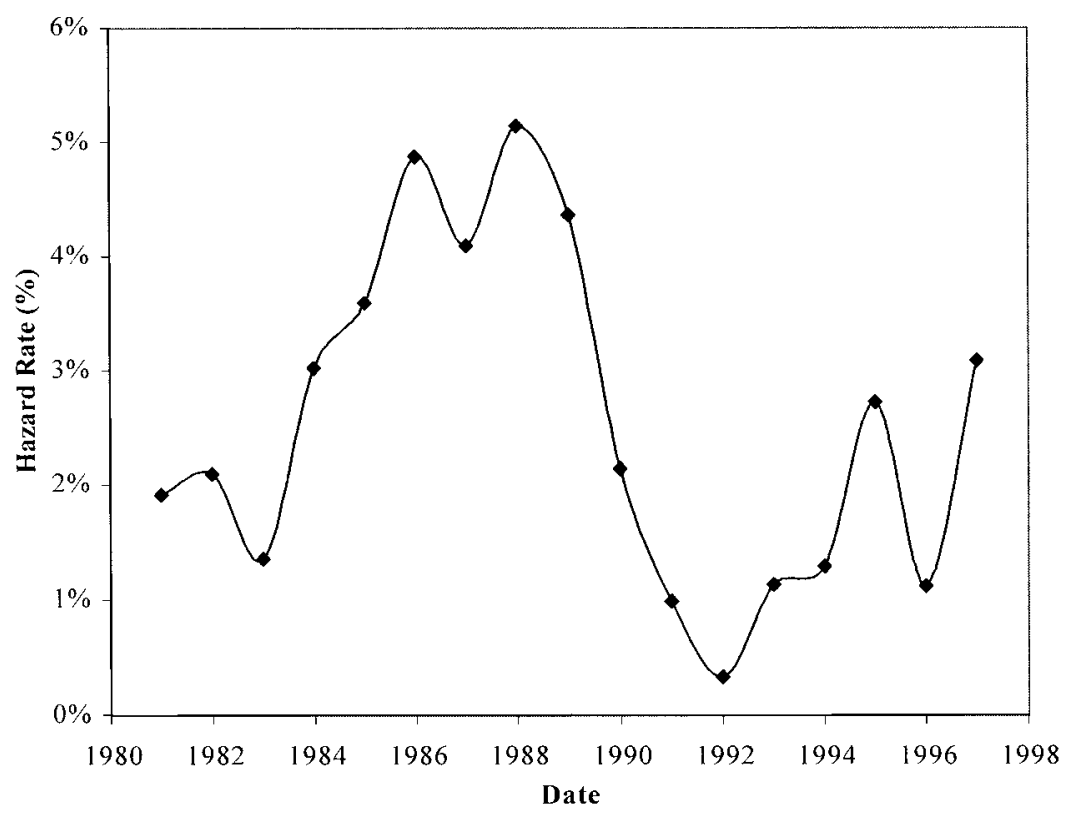

Figure 1. Annual Hazard Rate. [The simple annual hazard rate shown in the figure is calculated as (number of targets)/(total number of firms under study) per year. The date is the year of the takeovers used in the hazard rate.]

annum for the subperiod 1981-1989 is more than twice as large as the average annual rate of 1.6 percent for 1990-1997. In view of this apparent structural break in 1989, we present the descriptive statistics for the performance measures for the subperiods before and after the 1988 observations. ${ }^{15}$

Table A-2 in the Appendix presents a count of firms and targets for each year in our sample. Since the hazard models are estimated using annual data over seventeen years, and also use all historical data on a firm in relation to each hazard date, tables of annual means or medians are not informative in this context. Table 2 presents the median industry-adjusted performance measures for targets and non-targets in the two observation subperiods: 19801988 and 1989-1996. Furthermore, performance information for each firm is summarized by the average of the observations for a given performance measure during each of the subperiods. ${ }^{16}$ The top half of Table 2 presents the performance measures for non-targets in each of the two subperiods. Cost per unit of revenue indicates a very large and significant ( $p$-values < 0.01) improvement in the use of resources by non-targets during 1989-1996 as compared to $1980-1988 .{ }^{17}$

The bottom half of Table 2 displays the performance measures for targets in each of the two subperiods. These medians are further divided by the subperiod in which the firms were taken over. The relative cost-efficiency performance of targets in 1981-1989 is significantly worse than that of non-targets. "Later" targets, those firms that were taken over during the second subperiod 1990-1997, also underperform the non-targets during 1980-1988. As 
Table 2. Performance of targets and non-targets

For this table, each firm's performance was averaged during a given observation subperiod: 1980-1988 and 19891996. Cost is industry adjusted, calculated as firm minus the industry median, where industry median is matched on 2-digit SIC code and year of observation. The table entries are then the medians of those industry-adjusted averages of observations for firms. The target medians are bold where they are significantly different from non-targets in the same observation subperiod (1980-1988 or 1989-1996). Size is measured as revenue (net sales, \$millions, 1980). Cost is the (cost of goods sold plus selling, general and administrative expenses) per unit of revenue (\%). Number of 1990-1997 targets (63) that we have observations for in the subperiod 1989-1996 is smaller than the actual number of 1990-1997 targets (78), due to delayed entry of 15 firms.

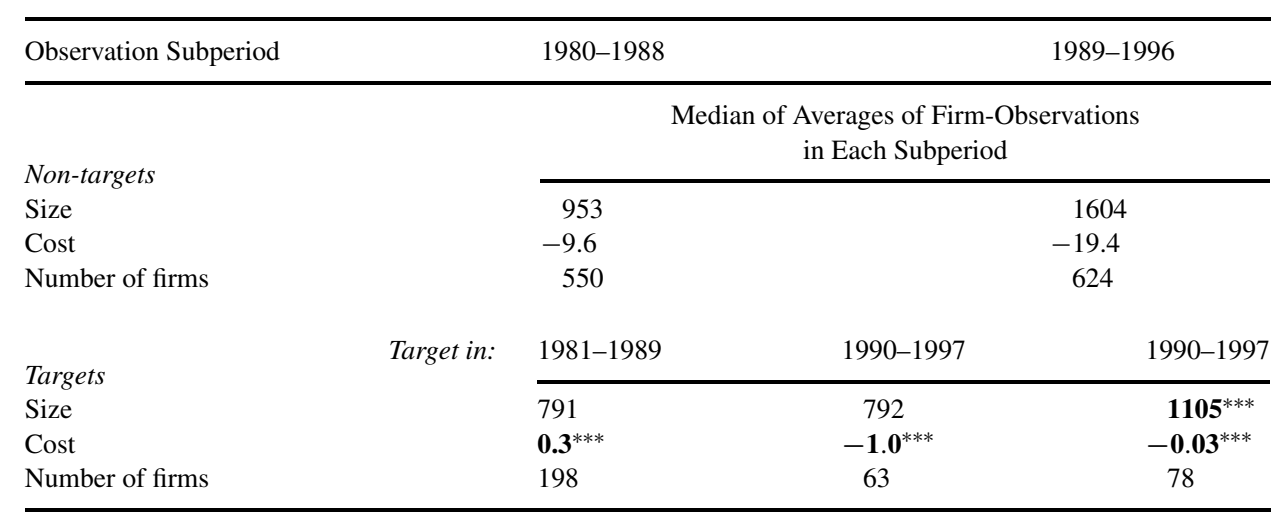

$* * *, * *$, and $*$ indicate Wilcoxon rank sum statistics significant at 1, 5 and 10 percent, respectively.

with non-targets, targets also improve over time. The gap between the cost performance of targets and non-targets widens substantially over time and remains highly significant.

In addition to the performance measures discussed above, Table 2 presents the statistics for the size of firms. It is important to note that the relative size of targets and non-targets changes across the two subperiods: while target and non-target size are not significantly different from each other during 1980-1988, targets are significantly smaller than nontargets during the 1989-1996 subperiod (discussion in the next section).

In summary, a striking feature of the data is that the performance of targets and non-targets varies over time. This suggests that a successful modeling of the risk of takeover requires not only the use of performance measures that best capture the performance gap between targets and non-targets, but also, and even more importantly, the use of statistical models and specifications that allow for changing effects over time of performance measures and other covariates on the risk of takeover.

\section{The Cox regression model}

This study employs the hazards regression model proposed by Cox (1972) as its statistical model. This model gained enormous popularity in the analysis of survival data in biostatistics for the features discussed below. Since takeover data in our study can be interpreted as survival data, the Cox regression model offers a powerful tool for modeling the dependence of the risk of takeover on firms' characteristics, and of the evolution of that risk over time. 
(An exhaustive discussion of the Cox regression model may be found in Kalbfleisch and Prentice (1980), Fleming and Harrington (1991) and Andersen et al. (1993). The first reference provides the most accessible discussion, whereas the other two are more mathematically demanding.)

Most studies use logistic and probit regressions to analyze takeover data. Those models estimate the probability of takeover over a fixed period of time as a function of a firm's characteristics at the beginning of the period. As such, these techniques are not suitable for the temporal profile of risk investigated here. The Cox model estimates the hazard rate of takeover at any time of the study period as a function of the history of time-dependent characteristics of a firm. It allows for the possibility of changing effects of these characteristics over time, as well as for the dependence of the effects on the levels of these characteristics.

The other notable feature of the Cox regression model, as compared with the logit and probit models, is that it accommodates right censored and left-truncated takeover times. The logit and probit models dichotomize the sample by a takeover outcome within the study period. However, the firm that has not experienced a takeover during the period of the study may be taken over within a year of the end of study. Thus inconsistent conclusions are likely to result merely from differences in the end points of the studies. ${ }^{18}$ In contrast, the Cox model considers such a firm as not having yet experienced a takeover, that is, as having a right-censored takeover time. The Cox model also accommodates delayed entry (left-truncated takeover times), that is, it does not require that all firms in the sample be followed from the beginning of the study. That requirement would have excluded over 200 firms from our sample. ${ }^{19}$ These features make the Cox model particularly suitable for studying the variation of takeover risk over time.

\section{Description of the model}

Our relatively brief exposition of the Cox model is in the context of the takeover data. Assume that all firms in our sample are at risk for takeover and let $T_{i}, 1 \leq i \leq n$, be the time to takeover (survival time) of the $i$ th firm in the sample. For this study we identify time 0 as year 1980 , and thus the time to takeover is measured relative to year 1980. The time to takeover of the $i$ th firm is assumed to depend on a vector $\left\{X_{i}^{*}(t), 0<t<T_{i}\right\}$ of its time-dependent characteristics or covariates. In the Cox model, the relation between the time to takeover and the covariates is modeled by specifying the form of the conditional hazard function of a takeover time. The conditional hazard function of a takeover time $T_{i}, \lambda\left(t \mid X_{i}(t)\right)$, for given covariates, is defined by

$$
\lambda\left(t \mid X_{i}(t)\right)=\lim _{\Delta t \rightarrow 0} P\left(T_{i}<t+\Delta t \mid T_{i} \geq t, X_{i}(t)\right) / \Delta t .
$$

It is seen from (1) that for small $\Delta t$

$$
\lambda\left(t \mid X_{i}(t)\right) \Delta t \approx P\left(T_{i}<t+\Delta t \mid T_{i} \geq t, X_{i}(t)\right),
$$


and thus $\lambda\left(t \mid X_{i}(t)\right)$ is approximately the probability that a firm experiences a takeover just after time $t$ given survival until time $t$ and given the covariates $X_{i}(t)$. Here $X_{i}(t)$ may be any suitable function of the history of covariates up until time $t,\left\{X_{i}^{*}(t), 0<t<T_{i}\right\}$, but in most applications of the hazard models it is assumed that the hazard of failure at time $t$ depends on the current values of the covariates, i.e., that $X_{i}(t)=X_{i}^{*}(t)$. Our specification of $X_{i}(t)$ involves lagged values of the covariates and is discussed below. The Cox hazard regression model specifies the following form for the conditional hazard function

$$
\lambda\left(t \mid X_{i}(t)\right)=\lambda_{0}(t) \exp \left(\beta^{\prime} X_{i}(t)\right),
$$

where $\beta^{\prime}=\left(\beta_{1}, \ldots, \beta_{k}\right)$ is a vector of unknown regression coefficients, $\lambda_{0}(t)$ is an unknown and unspecified baseline hazard function, and $\beta^{\prime} X_{i}(t)$ is an inner product.

An important aspect of the Cox model is that, at any point in time, the ratio of the hazard rates of takeover for two different firms does not involve the baseline hazard function. Consequently, in the case of time independent covariates, the ratio of hazard rates stays constant over time. For this reason, the Cox regression model is often referred to as the proportional hazards model. The parameter $\exp \left(\beta_{p}\right)$ represents a relative change in the hazard rate resulting from a one unit increase in the value of the $p$ th covariate, holding all other covariates constant, namely

$$
\exp \left(\beta_{p}\right)=\frac{\exp \left[\beta_{p}\left(X^{p}+1\right)\right]}{\exp \left[\beta_{p}\left(X^{P}\right)\right]}
$$

The baseline hazard function, $\lambda_{0}(t)$, gives the hazard rate for a firm with covariates equal to 0 . Since we use the cyclical consumer products sector as a baseline and we do not adjust the size variable, $\lambda_{0}(t) \exp \left(\beta_{\text {size }} S i z e\right)$ represents the hazard rate of a takeover faced by a firm in the cyclical consumer products sector of a given size, performing at its industry medians for all other performance measures.

The parameters of the Cox regression model are $\lambda_{0}(t)$ and the regression coefficients $\beta$. Cox (1972) proposed the partial likelihood method for the estimation of $\beta$. The essential feature of the method is that it does not involve the baseline hazard function $\lambda_{0}(t)$, that is, parameter $\beta$ can be estimated in the absence of knowledge of $\lambda_{0}(t)$. The baseline hazard function is estimated subsequently in a nonparametric fashion. Since in this study our interest is in the estimation of the relative risk of takeover faced by the firms, we discuss partial likelihood estimation of regression coefficients $\beta$, below. For a discussion of the estimation methods of $\lambda_{0}(t)$ we refer the reader to the aforementioned references.

\section{Takeover data and estimation}

For takeover data, as is typical for survival data in general, we do not observe the takeover times (i.e., survival times) for all firms and, furthermore, some firms may not be observed 
from the beginning of the study. Thus, for the $i$ th firm the observed data consist of the entry time $V_{i} \geq 0$, exit time, $\min \left(T_{i}, T\right)$, which is either a takeover time $T_{i}$, or the end of study time, $T$, whichever is smaller, and the covariate history $\left\{X_{i}^{*}(t), V_{i} \leq t<\min \left(T_{i}, T\right)\right\}$. Let $T_{(1)}<T_{(2)}<\cdots<T_{(L)}$ denote ordered observed takeover times. Let $(k)$ be the label for a firm experiencing a takeover at $T_{(k)}$, so the covariate history associated with label $(k)$ is $\left\{X_{(k)}^{*}(t), V_{(k)} \leq t<\min \left(T_{(k)}, T\right)\right\}$. Given these data and assuming that takeover times are all distinct, the regression coefficients, $\beta$, are estimated by the value $\hat{\beta}$ which maximizes the partial likelihood

$$
L(\beta)=\prod_{k=1}^{L} \frac{\exp \left[\beta^{\prime} X_{(k)}\left(T_{(k)}\right)\right]}{\sum_{j \in R_{k}} \exp \left[\beta^{\prime} X_{j}\left(T_{(k)}\right)\right]} .
$$

Here $R_{k}$ is the set of firms at risk of a takeover just before time $T_{(k)}$, that is, $R_{k}=$ $\left\{j: V_{j}<T_{(k)} \leq T_{j}\right\}$. We see that the partial likelihood is formed by taking the product over all takeover times. The $k$ th factor in this product:

$$
\frac{\exp \left[\beta^{\prime} X_{(k)}\left(T_{(k)}\right)\right]}{\sum_{j \in R_{k}} \exp \left[\beta^{\prime} X_{j}\left(T_{(k)}\right)\right]},
$$

is the conditional probability that the firm with covariates $X_{(k)}\left(T_{(k)}\right)$ is taken over at $T_{(k)}$ given that the firms in $R_{k}$ are at risk and that exactly one takeover occurs at $T_{(k)}$. We note that a firm that has not experienced a takeover during the time of the study contributes to the partial likelihood by its presence in some or all of the risk sets. Even though the partial likelihood $L(\beta)$ is not a likelihood function in the usual sense, it can be treated as an ordinary likelihood function for purposes of inference about $\beta$. Thus, under mild conditions $\hat{\beta}$ is asymptotically normally distributed with a covariance matrix that can be consistently estimated using either the usual matrix of second derivatives of $L(\beta)$ or, as is the case in this study, using the robust estimator of Lin and Wei (1989). Similarly, the inferences about inclusion/exclusion of the covariates can be based on likelihood ratio methods.

The derivation of the partial likelihood in (2) is based on the assumption that takeover times are continuous random variables and thus that no ties occur among takeover times. However, in many studies, including ours, time is measured discretely, which results in the presence of ties. ${ }^{20}$ When ties are present the following approximate partial likelihood has been proposed. As before, let $T_{(1)}<T_{(2)}<\cdots<T_{(L)}$ be the ordered takeover times. Let $d_{k}$ be the number of takeovers at $T_{(k)}$, and let $D_{k}$ be the set of firms that are taken over at $T_{(k)}$. The approximate partial likelihood is given by

$$
\widetilde{L(\beta)}=\prod_{k=1}^{L} \frac{\exp \left(\beta^{\prime} S_{k}\right)}{\left\{\sum_{j \in R_{k}} \exp \left[\beta^{\prime} X_{j}\left(T_{(k)}\right)\right]\right\}^{d_{k}}}
$$

where $S_{k}=\sum_{j \in D_{k}} X_{j}\left(T_{(k)}\right)$ and, as before, $R_{k}$ is the risk set at $T_{(k)}$. If there are ties, 
the regression coefficients, $\beta$, are estimated by the value $\hat{\beta}$ which maximizes (3). The approximate partial likelihood is accurate if, for all $k$, the number of ties, $d_{k}$, is small relative to the size of the risk set $R_{k}$. It can be seen from Figure 1 and Table A-2 that this condition is satisfied for our data; the ratio of the number of takeovers to the number of firms at risk is always less than 0.05 , and at most takeover times it is not greater than 0.03 .

In computing (3), we assume that $X_{j}\left(T_{(k)}\right)=X_{j}^{*}\left(T_{(k)}-1\right)$, that is, we assume, that the hazard of failure at $T_{(k)}$ depends on the values of covariates at time $T_{(k)}-1$. This is a natural assumption for our data: since performance measures are not available for the year in which a firm experiences a takeover, we use instead the last available values of performance measures from the year preceding the year of takeover.

In our application the Cox regression model is implemented using STATA (StataCorp., 1997).

The results: Size and cost inefficiency as determinants of takeover risk

Extensive statistical analysis of the model specification in Trimbath (2000a) suggests that the effects of size and cost on the risk of takeover depend on the magnitudes of these variables. Thus, the specification of our hazard model uses two size variables: one for larger firms whose size is above the sample median, and one for smaller firms whose size is below the sample median. In addition to the continuous cost variable, we include a dummy variable for firms with costs above their industry median.

Statistical analysis in Trimbath (2000a) also suggests a structural change in the parameters of the model across time. ${ }^{21}$ We therefore allow for a temporal change in the parameters of the model in 1988. We anticipate changes in capital markets to affect the impact of size on risk across time, whereas we expect cost efficiency to be temporally stable.

In addition to costs and size, our specification includes dummy variables indicating a firms sector. Beyond controlling for sectoral effects, these variables can also be interpreted as capturing the role of the takeover mechanism in reallocating resources across sectors. Since sectoral effects capture a complex process of the reallocation of resources through takeovers across sectors, we also do not expect them to remain stable over time. Changes in the economic environment, such as shifts in global trade or consumer demand as well as technical progress, are likely to affect the sector-related risk of takeover. Since these changes are inherently dynamic, we expect sectoral dummies to be temporally unstable.

Table 3 presents the results of the estimation of three hazard models. The model in the first column includes only the size variables. The models in the second and third columns include the cost variables, not split and split in 1988, respectively.

The results confirm our earlier observations based on the descriptive statistics. The effect of cost on the risk of takeover is positive and highly significant irrespective of whether the cost variables are split (column 3) or not (column 2) across subperiods. In addition to the marginal positive effect of cost on risk, firms with cost per unit of revenue above the industry median face a significantly greater risk of takeover. For example, an estimate of 
Table 3. Size and cost inefficiency and the risk of takeover

We estimate the risk of takeover based on size and costs using the Cox proportional hazard model with robust standard errors (Lin and Wei, 1989). Coefficients are the change in the logs-odds per unit. Standard errors are in parentheses, significant coefficients are bold-faced. Standard errors are adjusted for clustering on the firm identifier. Size is measured as revenue (net sales, \$millions, 1980). Size is split according to the medians of the sample in respective subperiods. Cost is the (cost of goods sold plus selling, general and administrative expenses) per unit of revenue (\%). Costs are adjusted for median performance in the same 2-digit SIC code industry and year. Cost above industry is a dummy variable equal one if the firm's cost is greater than the industry median, zero otherwise. Dummy variables for the economic sectors in each subperiod were included in the regression, but only significant coefficients are reported. Sector dummy variables are equal to one if the firm is in that sector and the observation is in that subperiod, zero otherwise. All models estimated using 896 firms, 276 takeovers and 10,784 observations.

Firms smaller than the sample median

Size, 1980-1988

$(0.00024)$

Size, 1989-1996

$-0.00040$

$\mathbf{0 . 0 0 0 5 4} 4^{* * *}$

$0.00057^{* * *}$

$(0.00033)$

$(0.00023)$

(0.0030)

$-0.00013$

Firms larger than the sample median

Size, 1980-1988

$\begin{array}{ccc}-0.00004^{*} & -0.00005^{* *} & -0.00004^{* *}\end{array}$

$(0.00002)$

$(0.00002)$

$(0.00002)$

Size, 1989-1996

$-0.00019 *$

$-0.00018^{* * *}$

$-\mathbf{0 . 0 0 0 1 8}^{* * *}$

Coefficients below this line are for all firms

$\begin{array}{lll}(0.00006) & (0.00005) & (0.00006)\end{array}$

Cost, 1980-1996

$\mathbf{0 . 0 1 8}^{* * *}$

(0.004)

$0.99 * * *$

Cost above industry, 1980-1996

$(0.15)$

Cost,1980-1988

(0.005)

Cost, 1989-1996

$\mathbf{0 . 0 1 6}^{* * *}$

(0.004)

Cost above industry, 1980-1988

$0.91^{* * *}$

(0.18)

Cost above industry, 1989-1996

Sectors

Non-cyclical consumer products, 1980-1988

Technology, 1980-1988

Technology, 1989-1996

Test statistics for the model

Degrees of freedom

Chi-squared

14

$41.1^{* * *}$

$* * *, * *$, and $*$ indicate test statistics significant at 1,5 and 10 percent, respectively. 
the cost dummy, reported in the second column of Table 3, implies that, ceteris paribus, a hypothetical firm with cost above the industry median, faces more than 2.5 times the risk of takeover than a firm with cost at the industry median.

The effects of the cost variables are not significantly different in the two subperiods: separate tests for equality of coefficients of the continuous and dummy cost variables fail to reject equality of coefficients (with $p$-values equal to 0.26 and 0.61 , respectively). We also note that the estimated coefficients of the other variables (size and sectoral dummies) remain virtually unchanged when the cost variables are split across the subperiods.

The results of the effect of size on risk, presented in Table 3, show that the magnitude and sign of the effect of size on risk are different in the two subperiods under study. For both smaller and larger firms, the effect of size on risk has become significantly more negative in the 1989-1996 subperiod as compared with 1980-1988 ( $p$-values for tests of equality in the two subperiods for smaller and larger firms are 0.035 and 0.016 , respectively). For smaller firms, the effect of size turns from positive and significant during 1980-1988 to negative (though not significant) during 1989-1996. For larger firms, the magnitude of the significantly negative coefficient of the size variable during 1980-1988 more than quadruples and becomes very highly significant during the 1989-1996 subperiod. Finally, it is remarkable that estimates of size coefficients appear to be "robust" with respect to a major change of the specification of the model: they remain virtually unchanged when cost variables are added (in models in columns 2 and 3 of Table 3 ) to the model containing only size variables and sectoral dummies (in column 1 of Table 3 ).

Prior studies of takeovers have suggested and often found that size has a negative effect on the risk of takeover. This negative effect of size on risk has been attributed to the difficulties in financing larger takeover transactions (for example, see Singh, 1975; Hasbrouck, 1985). However, the cost variable includes overhead costs, and thus the marginal increase in size enhances the potential for post-takeover gains in cost per unit of revenue. This implies that the effect of size on the risk of takeover might be either negative or positive and, in general, should be expected to vary over time depending on the relative strengths of these two opposing effects. In particular, during the periods in which financing of takeover transactions is relatively easy, the effect of size on risk is expected to be less negative - and perhaps even positive-as compared with the periods in which financing of takeovers is substantially more difficult. As discussed next, the 1980s were characterized by relatively easier access to financing for takeovers. Thus, we would expect the sign and magnitude of the size coefficient to change over time. The results in Table 3 are consistent with this interpretation.

Although an extensive analysis of a significantly more negative effect of size on the risk of takeovers during 1989-1996, as compared with 1980-1988, is beyond the scope of this paper, ${ }^{22}$ an explanation based on the changing costs and availability of financing of takeovers appears to have some plausibility. The early part of the 1980s included the introduction and rapid growth of the "junk bond era" of takeover financing. ${ }^{23}$ That era was also characterized by an antitrust environment favorable to large takeovers. By 1989, both the Federal Reserve and Congress had placed restrictions on "junk bonds" raising the cost of financing for large takeovers. ${ }^{24}$ 
Table 4. Relative risk for large targets in the two subperiods

The relative risk of takeover is estimated using the coefficients in the second column of Table 3 with the appropriate size coefficient corresponding to the observation year. The hypothetical size of each target firm in 1989-1996 is computed under the assumption that each of the firms would have grown at the same rate as the median firm. Estimates are relative to the firm with median size.

\begin{tabular}{lllll}
\hline & & & \multicolumn{2}{c}{ Estimated Relative Risk } \\
\cline { 4 - 5 } Target (date of takeover) & Size & Costs & Actual & Hypothetical in 1989-1996 \\
\hline Cities Service Co. (1982) & 7,763 & 0.090 & 2.26 & 0.45 \\
General Foods Corp. (1985) & 8,053 & 0.011 & 1.93 & 0.36 \\
RCA Corp. (1986) & 7,908 & 0.023 & 1.98 & 0.38 \\
Safeway Inc. (1986) & 17,319 & 0.004 & 1.20 & 0.02 \\
\hline
\end{tabular}

To gauge the numerical impact of the changing effect of size on risk, we consider two hypothetical firms with the same industry-adjusted cost per unit of revenue and in the same sector. Suppose that firm A had a size equal to the median of the sample in both subperiods: $\$ 968.43$ million and $\$ 1,151.64$ million, respectively, and firm B had a size equal to the third quartile of the sample in each of the subperiods: $\$ 2,565.69$ million and $\$ 3,849.95$ million, respectively. Using the estimates reported in the second column of Table 3, larger firm B faced a 6 percent lower risk of takeover during 1980-1988 than median firm A. This relative risk had fallen sharply after 1989. During 1989-1996, firm B faced a 34 percent lower risk of takeover than median firm A.

The impact of changes in the size effect estimated in Table 3 on hypothetical changes in risk across the two subperiods for four actual targets taken over before 1989 are presented in Table 4. To focus on the changing deterrent effect of the size of large firms between the two subperiods, we assume that the targets would have remained equally cost-inefficient in 1989-1996 as they were at the time of takeover. Since all firms in the sample grew between the two subperiods, we further assume that the four selected firms would have grown between the two subperiods at the same rate as the median firm. ${ }^{25}$ The actual targets presented in Table 4 illustrate that, due to the changing size effect, the risk of takeover faced by large cost-inefficient firms declined precipitously in the 1990s as compared with the 1980s.

\section{Data for the ex post analysis}

We continue our study using the same sample of firms for the ex post analysis as used in the analysis of the ex ante determinants of the risk of takeovers. To examine the impact of takeovers on the efficient use of resources, we matched pairs of firms combined in takeovers. In what follows, we describe the modifications made to prepare our data set for the ex post analysis. 


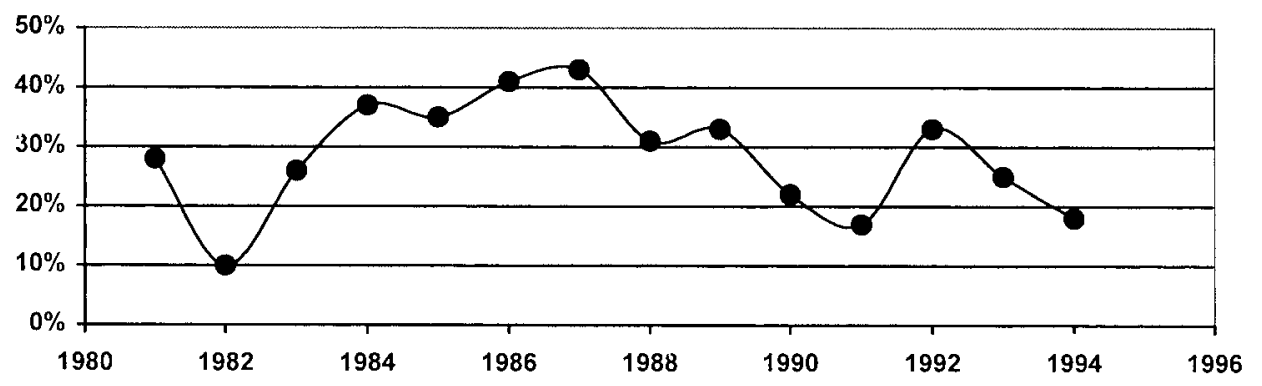

Figure 2. Relative Size of Paired Targets and Buyers. [The average size of targets relative to their buyers shown in the figure is calculated using Net Sales (revenue) in millions of 1980 dollars for each year. The date is the year the takeovers were completed.]

\section{Sample and data description}

For our analysis of the ex post effect of takeovers, we included any firm that was a partner in a takeover with our sample of Fortune 500 firms (i.e., firms that were buyers of or targets to firms in the sample). Firms not involved in takeovers and those without publicly traded partners were deleted from the sample. We were able to match 213 pairs merged through takeovers. Lack of data reduced our final sample to 165 pairs. For these, one additional firm was added as a buyer and 75 as targets; 86 pairs are made entirely from firms used in the $e x$ ante analysis. Figure 2 shows the relative size of the targets and buyers as measured by net sales (\$millions, 1980).

We use data from 1977 through 1996 for takeovers completed from 1981 through 1995. Table A-1 in the Appendix displays the sectoral distribution of the targets and buyers in the pairs. Table A-2 displays the number of pairs in the study by the year of their merger. The database in this section has 1,940 observations. Our ex ante benchmark is the pro forma (combined) performance of the target and buyer firms, following the same procedure used in Meeks (1977), Healy et al. (1992) and others, including weighted industry adjustments. This allows us to measure economic gains in the use of the combined resources that can be attributed to the takeover.

\section{Descriptive Statistics}

Although our regression analysis will account for temporal changes relating to the period in which a takeover occurred, the following descriptive statistics use all available data by year of takeover. We make the general distinction between ex ante and ex post observations. As shown in Table 5, the mean ex ante costs of the takeover pairs was 3 percent below industry (1 percent at the median). The mean ex post cost per unit of revenue in the sample was 6 percent below industry (4 percent at the median). While the univariate statistics are in no way conclusive, they are indicative of an important improvement in efficiency (reduction 
Table 5. Ex Ante and Ex Post performance of pairs

This table shows the pre-takeover performance based on pro forma combined target and buyer. The post-takeover performance is based on the combined firm after takeover. Cost is adjusted for 2-digit SIC code industry median in the year of observation. Cost is the (cost of goods sold plus selling, general and administrative expenses) per unit of revenue $(\%)$.

\begin{tabular}{lrr}
\hline & \multicolumn{2}{c}{ Cost } \\
\cline { 2 - 3 } & Pre & Post \\
\hline Mean & -3.4 & -5.5 \\
25th percentite & -6.8 & -9.5 \\
Median & -1.4 & -3.5 \\
75th percentite & 1.3 & 0.0 \\
$N$ & 638 & 556 \\
Pairs: 162 & & \\
\hline
\end{tabular}

in costs) that could be attributable to the combination of firms in takeovers. Overall, the buyers are the lower cost firm in the majority of pairs (62 percent, measured at the year before the takeover is completed). In the majority of those pairs (55 percent), the target's costs are above industry median.

\section{The fixed effects model}

Using fixed effects models in the manner usually applied in sociology studies, we sought to estimate the effect of takeover on firm performance, measuring changes from pre-takeover performance to post-takeover performance in the context of our data setting (see Allison, 1994). ${ }^{26}$

\section{Description of the model}

We begin with the following specification of the fixed effects model. Let $i$ index individual pairs, $t$ index time relative to the takeover, and let $Y_{i t}$ be the cost efficiency measure for pair $i$.

$$
Y_{i t}=\alpha_{i}+X_{i t} \beta+\varepsilon_{i t}
$$

$X_{i t}$ is the treatment variable, equal to one after the pair has combined in a takeover, and $\varepsilon_{i t}$ is the error term. ${ }^{27}$ The $\alpha_{i}$ 's represent differences across pairs that are constant over time and can be thought of as summarizing the effects on $Y$ of all unmeasured, stable characteristics of the pairs. The fixed effects specification in (4) assumes that pairs have unique distributions of unobservable characteristics that influence performance outcomes and is intended to control for differences in such characteristics between pairs. 
The coefficients of primary interest are the $\beta$ 's that measure the performance contrasts between ex ante and expost performance; we term them the takeover effects. These measure the effect of the takeover on $Y_{i t}$ that is common to all pairs (cross-sectional units). We estimate these effects for (i) all pairs combined in takeovers, (ii) pairs combined in different time periods.

The $\varepsilon_{i t}$ 's are the "usual" residual; the serially uncorrelated, transitory component of performance. The $\varepsilon$ variables represent time-specific random disturbances that are assumed to be independent of the measured explanatory variables, of $\alpha_{i}$, and of each other.

The fixed effects estimator controls for all stable differences across individuals, whether or not those differences are correlated with measured variables. The pair-specific effect $\left(\alpha_{i}\right)$ is identified and isolated, thereby removing omitted-variable bias from the parameter estimates.

This OLS method may not adequately deal with autocorrelation among the repeated observations. However, if the major component of these correlations is attributable to stable differences across pairs, the fixed effects estimator will probably correct for much of the cross-time correlation. Greater variation across individuals is more likely to result in greater correlation across the $Y_{i t}$ 's; this effect is adequately captured in the $\alpha_{i}$ 's.

\section{The results: Takeover effect on cost efficiency}

The takeover effect on costs is considered first in a regression representing the overall effect using one dummy variable for all ex post observations. This model identifies the effect of takeovers that is uniform for all pairs. Second, we use dummy variables for ex post observations on takeovers completed in the subperiods 1981-1989 and 1990-1995. These periods were identified as having significantly different determinants of the risk of takeover. The results are reported in Table 6.

There are significant cost efficiency gains in the post-takeover years. Across time, the efficiency gains are not statistically different $(p=0.97) .{ }^{28}$ Our analysis indicates significant improvements in efficiency for firms combined in takeovers. These gains are temporally stable.

Finally, to complete our analysis, we separate the marginal takeover effect in the same way as we did the takeover determinants. As shown in the bottom portion of Table 6 , takeovers resulted in significantly larger ex post improvements when the targets were larger $(p=0.041)$ and where targets were inefficient relative to their industry $(p=0.002)$.

\section{Conclusion}

The evidence presented in this paper suggests that a corporation faces a higher risk of takeover if it is relatively inefficient. Our variable capturing the cost inefficiency, relative to industry benchmarks, is temporally stable and thus we suggest it should be included in the specification of models of the risk of takeover. Furthermore, an examination of the takeover 
Table 6. Effect of takeovers on cost efficiency

Results of fixed-effects panel data models for the takeover effect on cost efficiency. The dependent variable is the cost per unit of revenue of firms that were combined in takeovers, with the treatment variable being equal to one for ex post observations (and limited alternately to the period of the takeover, the target's size relative to the sample median and the target's costs relative to its industry). Standard errors are in parentheses and significant coefficients are bold-faced. Pair effects (not reported here) are within pair. Costs are adjusted for 2-digit SIC code industry median in year of observation, weighted for the relative size of the target and buyer in the pair (if they were in different industries at the time of the takeover). Efficiency is measured as cost per unit of revenue (calculated as costs of goods sold plus selling, general and administrative expenses as a percent of sales).

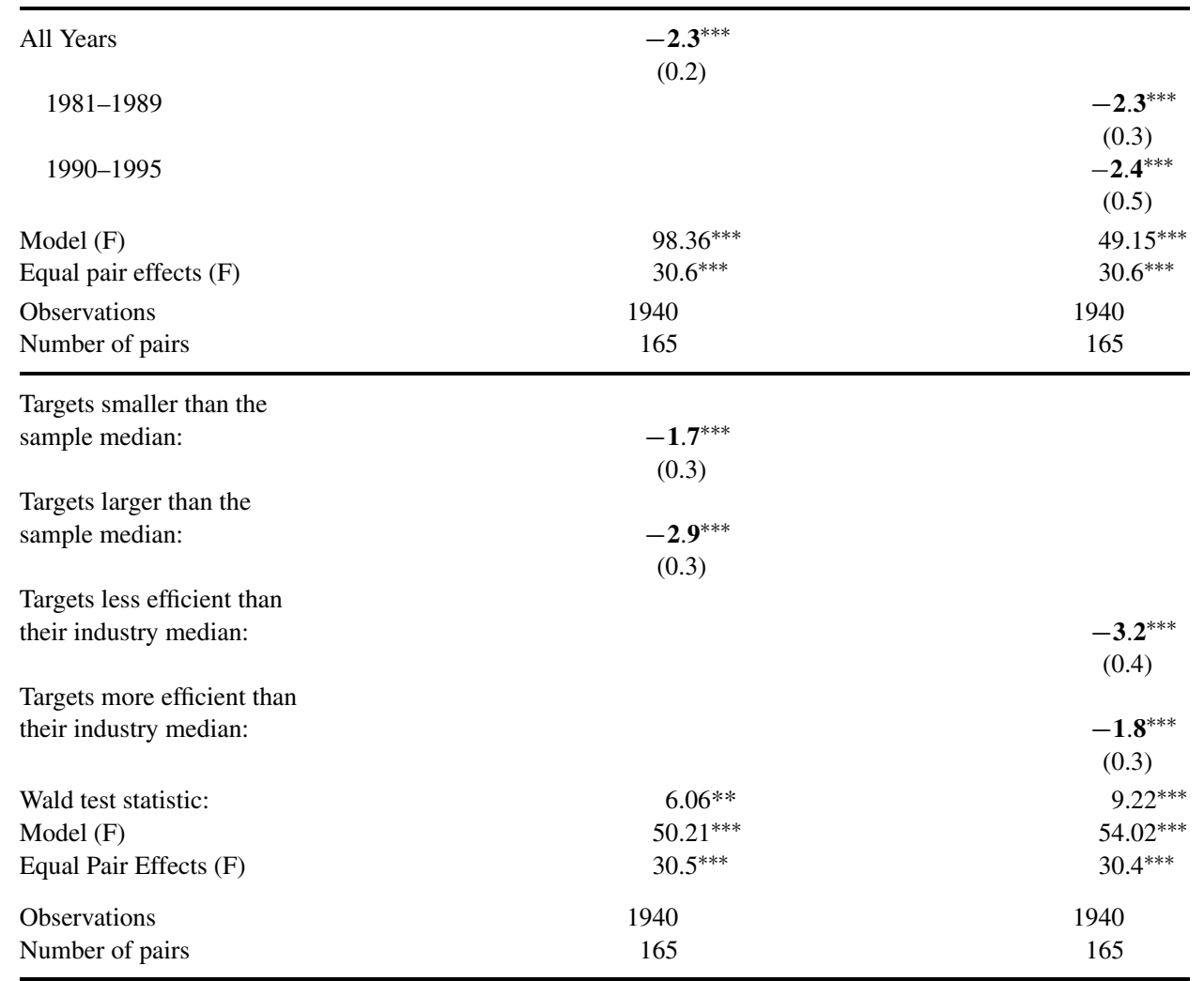

$* * *, * *$, and $*$ indicate test statistics significant at 1,5 and 10 percent, respectively.

effect on the ex post performance of paired firms demonstrates a significant improvement in cost efficiency which is, again, stable across time. ${ }^{29}$

We further demonstrate that the contribution of size as a risk factor can be affected by exogenous changes in the economic environment (likely due to changes in the capital markets). Our on-going research will produce a continuously updated database of takeovers, which can be used to identify additional temporal changes that may occur after the end of the current study. Lastly, we show that size can be a positive contributing factor to risk when we consider the potential gains that could motivate takeovers. 


\section{Appendix}

Table A-1. Sectoral distribution of sample firms

The number of firms in each sector is presented in this table. Every firm in the study is assigned to one of six sectors based on its industry. The sectors follow the definitions used in the Dow Jones Stoxx Index.

\begin{tabular}{|c|c|c|c|c|}
\hline & \multicolumn{2}{|c|}{ Ex Ante Sample } & \multicolumn{2}{|c|}{ Ex Post Sample } \\
\hline & Firms & Targets & Targets & Buyers \\
\hline Sector 1: Basic Resources & 160 & 45 & 18 & 22 \\
\hline Sector 2: Cyclical Consumer Products & 227 & 65 & 40 & 39 \\
\hline Sector 3: Non-cyclical Consumer Products & 171 & 60 & 38 & 38 \\
\hline Sector 4: Energy & 53 & 17 & 11 & 7 \\
\hline Sector 5: Industrial & 180 & 64 & 26 & 28 \\
\hline Sector 6: Technology & 105 & 25 & 32 & 31 \\
\hline All Sectors & 896 & 276 & 165 & 165 \\
\hline
\end{tabular}

Table A-2. Number of firms, targets, and pairs by year

This table gives the number of firms in the study for each year. The date is the year of observation for the sample used in the ex ante analysis and the year of the takeover for the sample used in the ex post analysis. Data on targets ends in the year before the takeover was completed. Hence, the 13 targets listed for Date 1980 were taken over in 1981, etc. The column total denotes the total number of firms in the sample. The number of firms each year differs from the total since some firms do not survive for the entire sample period and some firms enter with delay.

\begin{tabular}{llcc}
\hline & \multicolumn{2}{c}{ Ex Ante } & Ex Post \\
\cline { 2 - 3 } Date & Firms & Targets & Pairs \\
\hline 1980 & 679 & 13 & n.a. \\
1981 & 668 & 14 & 8 \\
1982 & 665 & 9 & 10 \\
1983 & 661 & 20 & 8 \\
1984 & 668 & 24 & 17 \\
1985 & 657 & 32 & 16 \\
1986 & 635 & 26 & 15 \\
1987 & 642 & 33 & 14 \\
1988 & 619 & 27 & 11 \\
1989 & 607 & 13 & 11 \\
1990 & 607 & 6 & 5 \\
1991 & 607 & 2 & 6 \\
1992 & 618 & 7 & 9 \\
1993 & 621 & 8 & 10 \\
1994 & 623 & 17 & 9 \\
1995 & 624 & 7 & $--*$ \\
1996 & 583 & 18 & 165 \\
Total & 896 & 276 & \\
\hline
\end{tabular}

*Observations end at 1996 so that no data is available for pairs merged in 1996 or 1997. Hence, the last takeover date for pairs is 1995 


\section{Acknowledgments}

The authors are pleased to acknowledge helpful conversations with Jason Cummins, Boyan Jovanovic, Joe Fuhrig and Edmund Phelps. Roman Frydman would like to thank the CV Starr Center for Applied Economics at New York University for support during the preparation of this paper.

\section{Notes}

1. In Trimbath, Frydman and Frydman (2000), we interpret our results following the distinction between the relative predictability of gains from revenue and cost restructuring, as advanced in the context of privatization in transition economies by Grosfeld and Roland (1997), Frydman et al. (1999) and Frydman, Hessel and Rapaczynski (2000). We also conjecture that the inconsistencies from different periods found in the literature on the effects of performance measures such as cash flow, profitability, or $q$ on the risk of takeover may be related to the ephemeral and firm-specific nature of revenue restructuring opportunities, such as developing new technologies or restructuring products.

2. For earlier evidence of changes in the risk-size relationship across time and/or across levels of size, see Herman and Lowenstein (1988), Powell (1997), Singh (1975) and Neumarke and Sharpe (1996).

3. See Mørck, Shleifer and Vishny (1988) for an example of the use of probit models and Palepu (1986) and Barnes (1999) for examples of the use of logit models in the context of takeovers. The only prior use of hazard models in the study of takeovers was Davis and Stout (1992) and Dickerson et al. (1998). Davis and Stout focused on the implications of takeovers for organizational theories of the firm. They did not examine changes in risk across time or levels of performance measures. Dickerson's study focused on dividend policy as the determinant of risk. They examined changes in marginal risk for dividends and investment only.

4. The sample periods were 1964-1972, 1962-1972, and selected years from 1968-1974 respectively.

5. These sample periods were 1979-1984, 1971-1981 and 1967-1987, respectively.

6. Some target firms will continue to report financial data to Compustat after a takeover if they have debt securities that remain publicly traded. Observations on known targets that post-date a takeover were excluded from our data set. Most of the firms in the study with initial public offerings after 1980 released some data to Compustat for years prior to the public offering date. Because those firms are not "at risk" before their initial public offering, those observations were also excluded from the analysis.

7. The study examined every firm in the sample to determine if that firm was involved in a takeover rather than relying on one listing of takeovers. The first source was the deletions list provided in Fortune's annual issue. This information was supplemented with Mergers and Acquisitions Almanac, CCH Capital Changes Reporter, Moody's Industrial and Transportation Manuals (corporate history), Hoover's Corporate Profiles and the footnotes and deletion codes to Compustat.

8. Since the performance of a firm and an industry median are likely to covary in response to macroeconomic (business cycle) shocks, regulatory and other changes in the environment, industry adjustment also makes the performance measures comparable across time.

9. For example Ravenscraft and Scherer (1987) used the equivalent of 1 minus (cost per unit of revenue) as a proxy for profitability.

10. We suggested earlier (Trimbath, Frydman and Frydman, 2000) that a shortfall in industry-adjusted profitability may signal the inefficient use of resources, though such a shortfall is likely to be a relatively more uncertain measure of the potential for gain from a takeover. Net profit rate, operating profit rate, labor productivity and a proxy for Tobin's $Q$ were also investigated using this sample and methodology. None produced temporally stable results or were significant in a model that included costs. (See Trimbath, Frydman and Frydman, 2000 for the results.) The same was true in regressions using shareholder returns and labor productivity as determinants of risk (Trimbath, 2000a). 
11. Previous studies used the book value of assets (Ravenscraft and Scherer, 1987; Cudd and Duggal, 2000) or market value of equity (Hasbrouck, 1985; Mørck, Schleifer and Vishny, 1989) in nominal dollars to measure size. The book value of assets may fall with depreciation even though the underlying assets remain in use at the firm. Market values are subject to intra-firm variation that may be more closely associated with changes in performance than firm size. Though sales seem a better measure of firm size and are superior as a direct cost-related indicator of potential short-run efficiency gains, in our sample of firms the three measures of size are highly correlated: the correlation coefficients for sales with assets and market value are 0.87 and 0.68 , respectively. The correlation coefficient for assets with market value is 0.67 . Moreover, the results concerning the effect of size on the risk of takeover reported in this paper remain virtually unchanged when assets or market value are used as measures of size instead of sales in the estimated hazard models.

12. As we discuss further below, we would expect the potential gains from takeovers of large inefficient firms to be significantly greater than gains from takeovers of smaller firms.

13. See the discussion below in the section on the results of the Cox model and reference therein for a more detailed discussion of the role of size for the risk of takeover.

14. Adjusting the size variable might also obscure its meaning. For example, the adjusted size of a large firm, which is smaller than the median firm in its industry, could be smaller than the adjusted size of a relatively small firm, which is larger than its industry median. However, these cases are rare in our sample and adjusted and unadjusted size variables are highly correlated (the correlation coefficient is 0.999). Furthermore, estimation results for hazard models using an adjusted size variable are very similar to the results reported here. For a detailed analysis of such models, see Trimbath (2000a).

15. In what follows, note that 1980-1988 observations are used to discuss takeovers completed in 1981-1989. Likewise for the later subperiod. The use of data for the year prior to the takeover is explained in detail in the section on the Cox Regression Model. The year 1988 is not chosen entirely arbitrarily. Structural changes relevant to our selection of this date will be discussed in more detail below.

16. Thus for targets during 1981-1989, observations used to compute averages of performance per subperiod are available only for part of the subperiod, that is until the year preceding the takeover. The same is true for averages over 1989-1996 for targets during 1990-1997. Note, however, that for targets during 1990-1997, averages of observations may be computed over the entire observation subperiod 1980-1988.

17. Detailed analysis of this phenomenon is outside the scope of this paper. It seems plausible, however, that the heightened threat of takeovers during the 1980's was an important factor behind the apparent drive by the managers of non-target firms to implement efficiency-enhancing restructuring of their firms.

18. For example, if a logit or probit model were estimated for our sample for the period 1980-1985, the 26 firms that were taken over in 1986 would have been considered as non-targets in 1985 .

19. As can be seen from Table A-2 in the Appendix, 217 firms had their initial public offering, and thus publicly available data, after 1980. Despite the unavailability of data for these firms for some time after the beginning of the study, these firms can be part of our sample.

20. In our study, time is measured in years relative to 1980 , so that possible values of takeover times are $1,2, \ldots$, 17, representing years 1981 to 1997

21. Specifically, there is a statistically significant interaction of size with time. More complex specifications of the temporal changes are possible. In the interest of clarity and brevity, we elect to present the model with only the most important structural break.

22. See Trimbath (2000b) for a more detailed discussion.

23. Several factors make it virtually impossible to collect reliable statistics on the use of high yield financing for takeovers. For competitive reasons, buyer firms may not reveal their intention to use the proceeds of new debt for takeovers. Conversely, firms that reveal their intention may not be successful in completing a takeover. Therefore, it is unlikely that we could statistically prove that a "junk bond era" existed, though it is widely believed to have been an important source of financing at the time, especially for the larger targets.

24. The market for high yield securities virtually collapsed at about the same time, thereby removing this source of financing altogether. The two events are not necessarily unrelated. See, for example, Lichtenberg (1992) for a discussion of the impact of consideration of the 1989 tax code change on the capital markets. 
25. Even under the assumption that these targets would have remained the same size, which would have made them much smaller relative to the median firm, the risk would have declined between the two subperiods due to the shifts of the size coefficients in Table 3. We also ignore the sectoral effects that, in any case, would have made the hypothetical decline of risk for the two firms in the non-cyclical consumer products sector, General Foods and Safeway, even greater.

26. This is essentially the same method that was applied in Healy et al. (1992).

27. A term $W_{i t s d} \delta_{s d}$ may be included (where $s$ indexes the target's economic sector and $d$ indexes the date (year) of the observation) to represent the $S^{*} D$ dummy variables for the target's economic sector and the date of the observation controlling for possible differences attributable to the macroeconomic environment across time and industry. The combination of the sector with the date allows us to include the sectoral effect in our specification, since time constant variables cannot be estimated in the fixed effects model.

28. The results are not changed when we include dummy variables for target's in the non-cyclical consumer products sector, which was shown in the previous section to have significantly different determinants.

29. Furthermore, our results are not sensitive to the method of payment. We used separate dummy variables for $e x$ post observations where pairs have below and above median changes in debt. This set of models is designed to control for the effect of takeover financing. A final set of regressions used the actual method of payment as a dummy variable. This set of regressions directly measures the impact of the method of financing (and therefore accounting) on the post-takeover performance of the firms. "Any cash" as the method of payment equates to using purchase accounting for the takeover. The change in debt and the method of payment were considered separately because the entire increase in debt may not be attributed to financing cash payments. The results of the primary model are not changed when controlling for the additional distinctions and are not reported here although they provide some evidence that our measure of efficiency is not infected by the different methods of accounting for the takeover. (See Trimbath, 2000a; for these results.)

\section{References}

Agrawal, A., J. F. Jaffe and G. N. Mandelker, "The Post-Merger Performance of Acquiring Firms: A Reexamination of an Anomaly." Journal of Finance 47(4), 1605-1660, (1992).

Allison, P. D., "Using Panel Data to Estimate the Effects of Events.” Sociological Methods and Research 23(2), 174-199, (1994).

Ambrose, B. W. and W. L. Megginson, “The Role of Asset Structure, Ownership Structure, and Takeover Defenses in Determining Acquisition Likelihood." Journal of Financial and Quantitative Analysis 27(4), 575-589, (1992).

Andersen, P. K., O. Borgan, R. D. Gill and N. Keiding, Statistical Models Based on Counting Processes. New York: Springer-Verlag, 1993.

Barnes, P., "Predicting UK Takeover Targets: Some Methodological Issues and an Empirical Study." Review of Quantitative Finance and Accounting 12(3), 283-301, (1999).

Billett, M. T., "Targeting Capital Structure: The Relationship Between Risky Debt and the Firm's Likelihood of Being Acquired." Journal of Business 69(2), 173-192, (1996).

Cannella, A. A. Jr. and D. C. Hambrick, "Effects of Executive Departures on the Performance of Acquired Firms." Strategic Management Journal 14, 137-152, (1993).

Cheh, J. J., R. S. Weinberg and K. C. Yook, "An Application of an Artificial Neural Network Investment System to Predict Takeover Targets." Journal of Applied Business Research 15, 33-45, (1999).

Cox, D. R., "Regression Models and Life-Tables." Journal of the Royal Statistical Society Series B 34, 187-220, (1972).

Cudd, M. and R. Duggal, "Industry Distributional Characteristics of Financial Ratios: An Acquisition Theory Application." The Financial Review 41, 105-120, (2000).

Davis, G, F. and S. K. Stout, "Organization Theory and The Market for Corporate Control: A Dynamic Analysis of the Characteristics of Large Takeover Targets, 1980-1990.” Administrative Science Quarterly 17, 605-633, (1992). 
Dickerson, A. P., H. D. Gibson and E. Tsakalotos, “Takeover Risk and Dividend Strategy: A Study of UK Firms." Journal of Industrial Economics 46(3), 281-300, (1998).

Fleming, T. R. and D. P. Harrington, Counting Processes and Survival Analysis. New York: Wiley, 1991.

Fowler, K. L. and D. R. Schmidt, "Determinants of Tender Offer Post-Acquisition Financial Performance.” Strategic Management Journal 10, 339-350, (1989).

Frydman, R., C. Gray, M. Hessel and A. Rapaczynski, "When Does Privatization Work? The Impact of Private Ownership on Corporate Performance in the Transition Economies." Quarterly Journal of Economics 114(4), 1153-1191, (1999).

Frydman, R., M. Hessel and A. Rapaczynski, "Why Ownership Matters: Politicization and Entrepreneurship in the Restructuring of Enterprises in Central Europe." mimeo, (2000).

Gregory, A., "An Examination of the Long Run Performance of UK Acquiring Firms.” Journal of Business Finance and Accounting 7/8, 971-1007, (1997).

Grosfeld, I. and G. Roland, "Defensive and Strategic Restructuring in Central European Enterprises." Journal of Transforming Economies and Societies 3, 21-46, (1997).

Hasbrouck, J., "The Characteristics of Takeover Targets: Q and Other Measures." Journal of Banking and Finance 9, 351-362, (1985).

Healy, P. M., K. G. Palepu and R. S. Ruback, “Does Corporate Performance Improve After Mergers?” Journal of Financial Economics 31, 135-175, (1992).

Heckman, J. J. and V. J. Hotz, "Choosing Among Alternative Nonexperimental Methods for Estimating the Impact of Social Programs: The Case of Manpower Training." Journal of the American Statistical Association, Applications and Case Studies 84(408), 862-880, (1989).

Herman, E. S and L. Lowenstein, "The Efficiency Effects of Hostile Takeovers," in Coffee, John C. Jr., Louis Lowenstein and Susan Rose-Ackerman (Eds.), Knights, Raiders and Targets: The Impact of Hostile Takeovers, pp. 211-240, New York: Oxford University Press, 1988.

Hsiao, C., T. W. Appelbe and C. R. Dineen, "A General Framework for Panel Data Models with an Application to Canadian Customer-Dialed Long Distance Telephone Service.” Journal of Econometrics 59, 63-86, (1993).

Jarrell, S. L., The Postmerger Performance of Corporate Takeovers, Working Paper, Wake Forest University, 1999. Kalbfleisch, J. D. and R. L. Prentice, The Statistical Analysis of Failure Time Data. New York: Wiley, 1980.

Kennedy, V. A. and R. J. Limmack, "Takeover Activity, CEO Turnover, and the Market for Corporate Control." Journal of Business Finance and Accounting 23(2), 267-285, (1996).

Kusewitt, J. B., Jr., “An Exploratory Study of Strategic Acquisition Factors Relating to Performance.” Strategic Management Journal 6, 151-169, (1985).

Lichtenberg, F. R., Corporate Takeovers and Productivity. Cambridge: MIT Press, 1992.

Lin, D. Y. and L. J. Wei, “The Robust Inference for the Cox Proportional Hazards Model.” Journal of the American Statistical Association 84(408), 1074-1078, (1989).

Martin, K. J. and J. J. McConne11, "Corporate Performance, Corporate Takeovers, and Management Turnover." Journal of Finance 46(2), 671-687, (1991).

Meeks, G., Disappointing Marriage: A Study of the Gains from Merger. Cambridge: Cambridge University Press, 1977.

Mørck, R., A. Shleifer and R. W. Vishny, "Characteristics of Targets of Hostile and Friendly Takeovers," in Auerbach, A. J. (Ed.), Corporate Takeovers: Causes and Consequences, Chicago: University of Chicago Press, 1988.

Mørck, R., A. Shleifer and R. W. Vishny, “Alternative Mechanisms for Corporate Control.” American Economic Review 79(4), 842-852, (1989).

Mueller, D. C., ed., The Determinants and Effects of Mergers: An International Comparison. Cambridge: Königstein/Ts, Oelgeschlager, Gunn \& Hain, Verlag A. Hain, 1980.

Neumark, D. and S. A. Sharpe, "Rents and Quasi Rents in the Wage Structure: Evidence from Hostile Takeovers." Industrial Relations 35(2), 145-179, (1996).

Opler, T. and J. F. Weston, The Impact of Mergers on Operating Performance, Working Paper, University of California, Los Angeles, 1992.

Palepu, K. G., "Predicting Takeover Targets: A Methodological and Empirical Analysis.” Journal of Accounting and Economics 8, 3-35, (1986). 
Pound, J., "Raiders, Targets, And Politics: The History and Future of American Corporate Control." Journal of Applied Corporate Finance 5, 6-18, (1992).

Powell, R. G., "Modeling Takeover Likelihood.” Journal of Business Finance and Accounting 24(7/8), 1009-1030, (1997).

Ravenscraft, D. J., and F. M., Scherer, Mergers, Sell-Offs, and Economic Efficiency. Washington, D.C.: Brookings Institution, 1987.

Singh, A., "Takeovers, Economic Natural Selection, and the Theory of the Firm: Evidence from the Postwar United Kingdom Experience." The Economic Journal 85, 497-515, (1975).

StataCorp., Stata Statistical Software: Release 5.0. College Station, TX: Stata Corporation, 1997.

Switzer, J. A., "Evidence on Real Gains in Corporate Acquisitions." Journal of Economics and Business 48, 443-460, (1996).

Trimbath, Susanne, The Evolution of the Determinants and Effects of Corporate Takeovers in the U. S., 1980-1997. Ann Arbor (MI): UMI Dissertation Services (Catalog Number 9970939), 2000a.

Trimbath, S., "High Yield Financing and Efficiency-Enhancing Takeovers." Milken Institute Policy Brief 22, (2000b).

Trimbath, S., H. Frydman and R. Frydman, Corporate Inefficiency and the Risk of Takeover, Working Paper 00-14, C. V. Starr Center for Applied Economics at New York University, 2000. 